\title{
GMO regulations and their interpretation: how EFSA's guidance on risk assessments of GMOs is bound to fail
}

Angelika Hilbeck ${ }^{1,2^{*}}$, Hartmut Meyer ${ }^{2}$, Brian Wynne ${ }^{2,3}$ and Erik Millstone ${ }^{2,4}$

\begin{abstract}
We identify the origins, and key characteristics, of the current regulatory framework for genetically modified organisms (GMOs) in the European Union (EU). We focus on the approach of the European Food Safety Authority (EFSA) to assessing GMO risks to public and environmental health. An historical account informs our critical appraisal of the current practices of EFSA's GMO panel, and helps to explain how and why it fails to satisfy the objectives of the EU's GMO legislation. While those legislative texts set appropriate objectives, their concrete implementation has fallen far short of the legislative goals. EFSA's prevailing approach to GM crop and food risk assessment starts from what it terms a'comparative safety assessment'. Those comparisons require the scrutiny of sets of molecular, chemical and phenotypic data from GM plants and non-GM varieties (many of which may be only remotely related to the GM variety). Those data are, however, inadequate for predicting adverse biological, toxicological and ecological effects. EFSA's 'comparative safety assessments' draw over-optimistic conclusions from too little data from too few studies. When GM products are deemed to have passed a'comparative safety assessment', EFSA has interpreted that as grounds for conducting only very narrowly circumscribed risk assessments, which have not required meaningful data from studies of ecological or eco-toxicological impacts. This is a reductionist approach to risk assessment, when a more inclusive and comprehensive approach, which we outline, is scientifically available, and also more likely to meet the specified legislative aims. Instead, however, the reductionist choice is systematically applied, but never justified nor acknowledged as such. Indeed, it is concealed, by EFSA and by its main policy client the European Commission, as if it were only for specialist expert scientific deliberation. Thus, key questions that sound scientific assessments should ask about potential harm are not even posed, let alone answered — or at least, they are 'answered' only by default, given that the implicit burden of proof requires harm to be demonstrated. Furthermore, and a key point of this paper, we show how the problematic features of EFSA's approach have been premised on a set of evaluative policy judgements, rather than purely scientific considerations. Responsibility for selecting how EFSA frames its scientific approach should however lie with European Commission risk managers, and not with EFSA. These problems might have been and could be avoided if explicit commitments entered into by the EU at the Codex Alimentarius Commission were implemented by the European Commission and EFSA were instructed accordingly.
\end{abstract}

Keywords: GMO, Regulation, Risk assessment, Biosafety, EFSA, Cartagena Protocol, EU Directive 2001/18, Codex Alimentarius Commission, Risk assessment policy

*Correspondence: angelika.hilbeck@env.ethz.ch

${ }^{2}$ European Network of Scientists for Social and Environmental Responsibility (ENSSER), Berlin, Germany

Full list of author information is available at the end of the article

\section{Background}

In this paper, we identify the origins, and analyze several key characteristics, of the current regulatory frameworks for genetically modified organisms, or GMOs, in the European Union (EU) (including, for the 
scope of this paper, also Switzerland and Norway). This requires, in particular, a practical understanding of the interpretive context in which the EU risk assessment methodologies for GMOs are designed and applied, in particular by the European Food Safety Authority (EFSA). Firstly, we provide an historical account that informs our critical appraisal of the current practices of EFSA's GMO risk assessment panel, and helps to explain why and how it fails to satisfy the objectives of the EU GMO regulations, namely to protect human health and the environment from adverse impacts. This historical context includes the development of EU and international regulations for controlling GMO cultivation and trade, which have reflected the different institutional and political-economic conditions where they were established.

The analysis in this paper is predicated on the assumption that, notwithstanding orthodox rhetoric and narratives, science-based risk policy-making is not, and cannot be, neatly compartmentalized into two discrete components. Orthodox accounts assume an up-stream stage that is purely scientific and a down-stream stage that exerts no influence on the science, but which rather combines the scientific advice that has been provided with non-scientific considerations concerning, for example, economic costs and societal judgements about the acceptability of, e.g., risks and costs. This paper, in contrast, assumes that scientific risk assessments are inevitably framed by some normative judgements about what counts as a relevant risk, what counts as relevant evidence, and how that evidence should be interpreted. The answers that scientific advisors provide to policy-makers depend on the questions that are asked, as well as the relevant evidence available. The choice of questions asked is, at least in part, unavoidably normative, which was first noted by Wynne [1] in four different case-studies, including environmental-agricultural ones, which he termed the "framing issue". It has since then been widely accepted, and was adopted in 2007 by the UN FAO and WHO Codex Alimentarius Commission [2], using the appropriate term, risk assessment policy [3]. That perspective informs both the empirical analysis this paper provides, and the policy-relevant conclusions that are drawn from the analysis. We identify a repeated confusion, not only at EFSA but much more broadly within science itself as well as policy, between risk-scientific issues and choices, and policy-laden normative choices in framing the technical-scientific questions and criteria. As this paper unavoidably engages with both scientific and policy considerations, an explicit acknowledgement of the assumed relationship between those two types of considerations is preferable to pretending they are confined to two separate and independent compartments.

\section{The US approach to GM regulation}

When Cohen reported in 1975 that DNA could be transferred between species, suggesting the invention or creation of novel varieties and species (called genetically modified organisms, GMOs), US federal legislators started drafting regulations that would apply to GMOs [4]. This immediately alerted those scientists and industrialists who anticipated large economic gains from their research, in part because of the prospect of inventors or their institutional employers to obtain patent protection [5-7]. Consequently, in 1977, a Congressional Bill to regulate GMOs was blocked, after Cohen managed to convince legislators that the products of the new technology could also have appeared in nature through spontaneous mutations [8, 9]. Expecting a revolution in biology and immense business opportunities, genetic engineering was declared by the US government for risk regulatory purposes as 'equivalent to' conventional breeding methods, meaning a GMO is not legally deemed to be a novel organism, that could pose unforeseeable risks, and, therefore, does not require specific sui generis safety regulation $[8,9]$.

The US government's view that GMOs are so uniquely novel that they deserve patent protection, while they are also so ordinary that they deserve no safety review or testing, always was anomalous. But, understandably, biotechnology companies were keen for the same anomaly to be accepted in the EU, and in other prospective markets. Consequently today, the claim that GM crops and foods are no different from, and no less safe than, plants and animals that have evolved naturally, or are products of human selective breeding, is a familiar narrative (e.g., $[10,11])$. It has been articulated for decades by biotechnology companies and their scientific and regulatory collaborators, and is used to argue either for no regulations, or at most, for a light-touch regulatory regime. The same narrative has been widely re-invoked recently for so-called 'gene-editing' methods, such as Crispr/Cas, although it was not endorsed by the European Court of Justice, which ruled that agricultural products developed by such 'gene-editing' methods are within the scope of EU legislation on GMOs [12], and thus (unlike in the USA) require specific prior human health and environmental risk assessment [13].

In 1976, the US National Institutes of Health (NIH) adopted guidelines on ensuring safety, which set out a system based on biological and physical containment, but it applied only to scientists and projects funded by the NIH, not to independent or commercial labs, or even to research funded by other US public agencies. Subsequently, in 1983, the US National Research Council [14] published a study to explore the feasibility of uniform risk assessment guidelines (for cancer and other health 
related risks from chemicals and related new commercial products) for use by all regulatory agencies. This authoritative report separated 'risk assessment' as a supposedly independent and prior scientific activity from risk management decision-making which should be based on the scientific risk assessment, but which also takes account of non-scientific considerations such as economic costs and benefits and judgements about what levels of risk could be deemed acceptable. When, in 1983, the first GM bacteria and GM plants were released in field trials in California, the prevailing health protection guidelines, which had been routinely used for conventionally produced plants, were followed to assess possible environmental risks [15]. Thus, the USA opted to apply an existing legislative and regulatory framework designed for non-GM products, rather than to establish GMO-specific legislation or regulation. This was very different from the EU's approach, promulgated in the 1990 EU Directive 220, which required specific prior risk assessment for GMOs, whether intended for lab-confinement or for environmental release [16].

The US approach came to be termed a 'product-based' approach, because it has not been concerned about the particular technologies that produce GMOs, but only about the novel characteristics of the GM end-products. In the USA, those GM products have been judged by reference to estimates of biochemical similarities to, and differences between, the GM products and a range of their non-GM counterparts. The idea, in theory, is that if the results of such 'comparative analyses of the relevant characteristics of the GM plant' $[17,18]$ resting primarily on the 'comparative compositional assessment (FAO/ WHO 2000, OECD 1993)' [17, 18] of basic plant compounds (such as total fat, fatty acid, fiber, protein, ash, amino acids, vitamins, minerals and, on occasion at the discretion of the producers, some secondary metabolites) differ significantly between a GM product and its nonGM counterparts (especially the non-engineered parent organism that has served as recipient organism of the new transgenic traits), then it could trigger a fuller risk assessment. However, in reality, that hardly ever happens, since there are no cut-off thresholds for the potentially significant estimated differences that would trigger such an additional assessment. That approach will be described in more detail below, in relation to the initial concept of 'substantial equivalence' which subsequently became the basis for EFSA's 'comparative safety assessment approach'. Ironically, that approach has never been applied in practice to new conventionally bred crops, but only to those developed by genetic engineering. The US regime for GMOs was, therefore, different from that for its non-GM counterparts, despite being officially portrayed as if providing exactly the same treatment.

\section{EU and international approaches}

In contrast to the USA, the debate in EU member states extended far beyond closed expert circles and from the start involved civil society groups including independent scientists. Civil society organizations strongly opposed the US approach, which they saw as biased in favor of pursuing the commercial prospects of genetic engineering, to the neglect of possible risks, and by denying the 'novelty' of GMOs in relation to risk/safety assessment, while insisting on 'novelty' when it permitted patenting. While many European governments originally adopted the model of the US NIH guidelines, by the late 1980s the emergent public debate had concluded that an overarching, specific legal framework for all types of agricultural applications of genetic technologies was necessary, because of the 'novelty' of GMOs $[8,16]$. The EU approach shares with its US counterpart the assumption that, in respect of 'intellectual property rights', GMOs are novel. The EU permits novel GM agricultural products and processes to be patented, but correspondingly also deems the GMOs to be novel in respect of requiring their sale and use to comply with regulations concerning efficacy and safety. The EU, therefore, never adopted or endorsed the US system, and, as from the early 1990 regulations, covered both products and processes.

The first European domestic GMO biosafety frameworks were adopted in Denmark in 1986 and Germany in 1990 [19-21]. Legally binding European biosafety regulations followed in 1990 [16]. Eleven years later that Directive was replaced by EU Directive 2001/18 [22], partly in response to the BSE crisis of March 1996, and the recognition that BSE had been mistakenly assumed to be 'substantially equivalent' to the familiar sheep disease known as scrapie. Evidently, superficial similarity as determined by substantial equivalence assessments of individual chemical components had not been a sufficient guarantee of safety. The 2001/18 Directive also reflected the EU's decade-or-more experience that the original GMO risk assessments since Directive 1990/220 had failed to address scientifically recognized indirect, cumulative or long-term environmental and health risks from GMOs. As a result, assessing those types of risk were made new explicit requirements of EU and the member states' risk assessment agencies, the prime one being EFSA. Prior to 2002, it was the Scientific Committee of Plants (SCP) that provided scientific advice on GM risks to the EU Commission, though it also adopted a reductionist scientific approach.

The currently prevailing EU Directive 2001/18 (amended by Directive 2018/315 in March 2018), regulating GM crops for environmental release, requires a risk assessment of GMOs that are intended to be released into the environment. The Directive identifies and names 
the subject of regulations as 'organisms' and its objectives require the protection of human health and the environment in the event of the commercial introduction of GMOs. It is important to recognize that organisms are not simply the sum of their constituent molecules. Organisms respire, digest and excrete, as well as reproduce and die, all of which are beyond the capabilities of individual chemical molecules of which organisms are composed. And due to these capabilities, living organisms can exhibit complex, unexpected, emergent properties that cannot be predicted from the sum of their individual added chemical compounds. This becomes relevant when we discuss the reductionistic practical implementation of these regulations.

The UN Cartagena Protocol on Biosafety (called the Protocol hereafter) [23, 24] was strongly influenced by the legal text of the earlier 1990 Directive [16]. The Protocol is an international agreement under the Convention on Biological Diversity, which aims to ensure the safe handling, transport and use of GMOs that may have adverse effects on biological diversity, also taking account of risks to human health [25, 26]. It also treats GM organisms, (in the Protocol called Living Modified Organisms, LMOs), as an obligatory and scientifically required object of regulations. Both legal texts define GMOs or LMOs by reference to the application of certain technologies to introduce new, or to alter, genetic material in organisms, which could not be produced through natural processes. Although not mentioned explicitly in the legal texts, the basic assumption is that due to the manmade and technology-based introduction of new genes, no evolutionary selection or normal testing of 'fitness' has taken place to influence their survival, or to reduce or reveal potential ecological and/or health risks. Consequently, an official ex ante scientific risk assessment has to be conducted before permitting a release of such organisms into the environment, as the consequences of such releases could well be irreversible and hard to predict. From this perspective, the EU and the international approaches, opened the possibility to develop adequate, scientifically sound risk assessment methodologies, going beyond the deliberately limited and voluntary US consultative approach to facilitate technology promotion. However, by opening that possibility of scientifically sound risk assessment in the EU, it does not automatically follow that public and environmental health are adequately protected.

\section{Different concepts for risk assessment}

International and European regulatory regimes governing the safety of the production and sale of GMOs (or LMOs) are framed by a recognition that the process of genetic engineering-regardless through which technique(s) it is achieved-raises novel issues of risk and safety. The same applies for new genetic engineering techniques that some commercial and scientific interests-again-claim are so controlled and precise that they do not require specific process-based risk assessment [12, 13]. Such regulatory regimes recognize that processes to engineer DNA sequences in novel ways, which previously were not possible, could result in unintended and scientifically unanticipated genotypic and phenotypic novelties the safety of which, for public and environmental health, cannot simply be assumed (for recent examples, see e.g., Martineau [27] commenting on Norris et al. [28]; Wilson [29] commenting on Bollinedi et al. [30]). Regulatory judgements must, therefore, be based on scientific evidence and expert advice. That advice should be based on assessments of both the scope and the limits of the available evidence and understanding. Traditional breeding techniques, which work within the reproductive boundaries of individual species or at a population level, bring about gradual changes to organisms and populations, and have been effectively tested and often used safely for millennia, with problematic novelties occurring rarely or being readily detectable [31]. In Europe and elsewhere, genetically engineered genotypes, regardless of which genetic engineering tools were used for their production (older or newer), are categorized as novel human innovations, not products of evolution and natural selection or conventional deliberate crossbreeding. In many, but not all, jurisdictions GMOs are therefore deemed patentable. By virtue of that novelty, GMOs have no (evolutionary) history of use, let alone 'safe use', and, therefore, questions about their safety beyond those of conventional crossbreeding are scientifically legitimate and politically unavoidable.

Only genetic engineering methods, not traditional breeding or mutagenesis, can facilitate the use of genetic material between distant taxa (e.g., viral promotors, transit proteins, etc.), thus, enabling genomic changes which cannot be achieved by vertical (inherited) gene transfer. This raised concerns among geneticists, ecologists, evolutionary biologists and toxicologists that genetic engineering could lead to higher rates of hard-to-predict molecular genetic changes. Those can arise because of uncontrolled re-arrangements of DNA due to the random insertions of additional DNA, which can include position effects and/or pleiotropic effects (for review see $[28,32])$. Supposedly small, single gene changes can provoke multiple knock-on effects. Genetic engineering can also provoke re-arrangements and alterations of the epigenome, i.e., non-DNA-based heritable traits that can be transferred for example via the methylation of DNA (see e.g., [32, 33]). All such changes are different from, and go beyond, those that occur through conventional 
Table 1 Different headings for the 6 steps of ERA, in EU Directive 2001/18 [22] and the EFSA Guidance [17]

\begin{tabular}{|c|c|}
\hline Directive 2001/18 & EFSA 2010 guidance \\
\hline 1. Identification of characteristics which may cause adverse effects & 1. Problem formulation including hazard identification \\
\hline 2. Evaluation of the potential consequences of each adverse effect, if it occurs & 2. Hazard characterisation \\
\hline 3. Evaluation of the likelihood of the occurrence of each identified potential adverse effect & 3. Exposure characterisation \\
\hline 4. Estimation of the risk posed by each identified characteristic of the $\mathrm{GMO}(\mathrm{s})$ & 4. Risk characterisation \\
\hline $\begin{array}{l}\text { 5. Application of management strategies for risks from the deliberate release or marketing of } \\
\mathrm{GMO}(\mathrm{s})\end{array}$ & 5. Risk management strategies \\
\hline 6. Determination of the overall risk of the $\mathrm{GMO}(\mathrm{s})$ & 6. Overall risk evaluation and conclusions \\
\hline
\end{tabular}

crossbreeding methods, and they cannot, yet at any rate, be reliably predicted or controlled, nor can they be reproduced (e.g., [32, 33]). On that empirical and normative basis, EU legislation, regulations and some implementation guidance were developed by the EU Commission (as risk managers) and by EFSA (as risk assessors), which differ significantly from the voluntary light-touch regime of the USA [34].

Despite these clear conceptual differences between the EU and US risk assessment approaches, based on competing legal norms, biotechnology companies, their collaborating scientists and lobby groups have worked relentlessly on developing risk assessment schemes, technical definitions and decision-rules, and implementation guidelines, and on influencing the institutions involved, so as to make the actual EU technical requirements for approval of GMOs as similar as possible to the US approach ([35-38] and references therein). While full regulatory transatlantic harmonization of the legal frameworks has not been possible until now (i.e., 2020), some harmonization at the technical level of risk assessment can be observed, which we will highlight by analyzing the guidance documents developed by EFSA on how to conduct risk assessments of GM crops-both for environmental release [17] and for food and feed [18].

\section{A critical appraisal of EFSA's guidance on environmental risk assessment (ERA) and on risk assessment of food and feed of genetically modified plants}

According to EU Directive 2001/18 [22], “...the objective of the ERA is on a case-by-case basis to identify and evaluate potential adverse effects of the GM plant, direct and indirect, immediate or delayed (including cumulative long-term effects) on the receiving environment(s) where the GM plant will be released." (op cit L 106/19). The interpretation and implementation of those stipulations by EFSA remains however highly controversial, with EFSA and other scientific groups interpreting them very differently and arriving at contrasting conclusions about possible risks. Those different judgements, which imply differing conclusions about safety or potential risks, that in the absence of evidence would require regulatory control under the EU Treaty commitment to the Precautionary Principle, are supposed to be identified and acknowledged by EFSA, and a procedure should have been established for their resolution. But this legal requirement of EFSA's regulatory practice has never been properly implemented. Nor has this lack been acknowledged and addressed by the European Commission, as policy client of its scientific adviser, EFSA.

Evidence supporting that contention is provided by the text of the corresponding guidance documents developed by EFSA's GMO panel $[17,18]$. In those documents EFSA has, in effect, provided guidance to itself and member-states about how to interpret the requirement to conduct risk assessments of GMOs (here only GM plants), as laid out by the EU Directive 2001/18 [22]. The EFSA 2010 guidance [17] on environmental risk assessment of GMOs in particular was based on the narrowest possible interpretation of the six risk assessment steps set out in Table 1.

As we will show, the EFSA guidance rests almost entirely on concepts developed either directly by corporate applicants or by applicant-aligned consortia, i.e., not by independent scientists, or by publicly accountable policy-makers. Alternative concepts favoring a broader and more comprehensive, and ecologically realistic, approach developed by scientists working independently of commercial and/or industrial applicants, which were available to EFSA, were mostly or completely ignored, as we shall show below. Those more inclusive, less reductionistic approaches are, importantly, far more consistent with the legal stipulations in EU Directive 2001/18 than the approach adopted by EFSA's GMO panel. In this paper, we highlight the consequent shortcomings in EFSA GMO risk assessment guidances along 3 types of action taken by the EFSA GMO panel: introducing a new, uncalled-for stipulation, and altering (two) existing stipulations-all of which lead further to a narrowly construed scientific approach in risk assessments that is particularly advocated by commercial stakeholders. 
EFSA introduces a 'problem formulation' step and a comparative (safety) assessment (approach) before a risk assessment is conducted

The introduction of a 'problem formulation' step need not be controversial and could well be justified, indeed in principle it is consistent with the risk assessment policy (RAP) stage mandated by Codex Alimentarius [2, 3] which we analyze below. "Problem-formulation" for risk assessment, and "RAP", are-or ought to be-virtually the same. However, in this case, the way the EFSA GMO panel has framed the problem is itself problematic, both procedurally and substantively. It also obscures deeper problems in the way both the European Commission, as policy agent, and EFSA, as scientific 'adviser', (mis)understand and enact those formal roles.

In procedural terms, an explicit, internationally agreed protocol for deciding the problem framing (or problem formulation) stage prior to risk assessment was defined by the Codex Alimentarius Commission (aka Codex). Codex used the phrase 'RAP' to refer to the task of selecting a framing of the problems and questions to which expert risk assessors are expected to respond. It is not clear why EFSA and its European Commission risk managers failed to adopt that alreadyagreed global terminology, when the EU as overall policy authority had already ratified this Treaty. But however it is referred to, it is important to appreciate that the specific way in which the GMO Panel framed the parameters of its risk assessments, and the procedure by which that framing was decided, had profound and unacceptable implications as we show below.

Codex was established in 1961 under the joint auspices of the World Health Organization and the UN Food and Agriculture Organization. It sets internationally recognized minimum baseline standards (as well as issuing codes of practice, guidelines and other recommendations) in relation to food production and food safety in international traded products (see http://www.fao.org/ fao-who-codexalimentarius/en/). All Codex memberstates, which include all EU Member States and the EU itself, committed themselves in 2007 to explicitly articulating RAPs for scientific risk assessments. It seems that this general commitment was never converted into practical, domain-specific practice-certainly not for agricultural biotechnologies (GMOs).

Codex has defined RAP as "Documented guidelines on the choice of options and associated judgements for their application at appropriate decision points in the risk assessment such that the scientific integrity of the process is maintained" ([2]-emphasis added in bold).

The Codex Procedural Manual stipulates that:
- "Determination of RAP should be included as a specific component of risk management.

- Risk assessment policy should be established by risk managers in advance of risk assessment, in consultation with risk assessors and all other interested parties. This procedure aims at ensuring that the risk assessment is systematic, complete, unbiased and transparent.

- The mandate given by risk managers to risk assessors should be as clear as possible." ([2], Appendix IV paras. 13-16-emphases added in bold).

Empirical studies have indicated that, in technology policy debates of this type, at least three main types of RAP issues are in play, namely: substantive, procedural and interpretative [3]. Substantive RAP is concerned with what is, and is not, deemed to constitute a 'risk', and therefore what do, and do not, count as relevant questions, factors and evidence. We argue that EFSA's GMO panel has chosen to adopt a narrow framing, and, consequently, it has only assessed a few sub-sets of possible risks and has only required relatively modest amounts of evidence. Procedural RAP is concerned with how risk assessments are to be framed and then conducted, as tasks distributed between policy actors and scientific actors. The EFSA GMO panel-a scientific panel-has chosen to hold all its meetings in closed sessions, it has invoked an up-stream 'comparative safety assessment' which involves normative, thus, policy choices, and used it to constrain the scope of any subsequent risk assessment. It has been prepared to accept unpublished industry data, and to keep those data from wider, easily accessible scrutiny. These are policy as well as scientific choices, and should, therefore, be the risk-managers' domain, not EFSA's alone. Interpretative RAP is concerned with how evidence is to be interpreted, including whether it is defined as relevant or irrelevant, and judgements concerning how much of which kinds of evidence is deemed variously to be necessary and/or sufficient to support recommendations to permit, restrict or forbid some product or process. EFSA's GMO panel has chosen to deem GMOs as posing no risks to public or environmental health on the basis of those selectively limited amounts of evidence.

Given that the EU committed itself to implementing the Codex RAP procedure, it should have been followed in its regulation of agricultural biotechnology, but in practice something else occurred. Firstly, risk managers, in the Directorate General for Health and Food Safety (or DG-Sante) in the European Commission, played no acknowledged role in deciding how the risk assessment problem of agricultural biotechnology should be framed. Instead, the decision emerged from EFSA, which is 
ostensibly a scientific 'risk assessor' not a policy-making 'risk manager'. The Chief Executive of EFSA has acknowledged that EFSA is supposed to be a purely scientific body, giving advice but with no statutory responsibility for policy decisions [39]. In practice, however, numerous policy choices have been autonomously made by EFSA risk assessors concerning the problem-framing they adopted, without the involvement of, or reference to, risk managers [40, 41].

Consequently, a key, irredeemably normative RAP judgement has been mis-represented both by EFSA and by the European Commission as if it was a purely scientific judgement. Moreover, the procedure by which those risk assessment policies were decided by EFSA's GMO risk assessors excluded all but a few of "...all other interested parties., which Codex requires. While representatives of some specialist public and environmental health organizations responded to the consultation, many others were unable to do so. Furthermore, the procedure did not ensure that risk assessments are systematic, complete, unbiased or transparent; on the contrary, as we argue below, they have been partial rather than systematic, as well as incomplete, biased and, in key respects, opaque.

The EFSA GMO panel's approach, in its 2010 guidance on environmental risk assessments framed the risk assessment problem as that of identifying the characteristics of GMOs that are most likely to cause adverse effects [17]. The Panel chose to design and implement that procedure in the context of what it terms a 'comparative safety assessment' (see Table 1 and further discussion below in "EU and international approaches" section). With alternative options available, the Panel chose to interpret that concept in a particularly narrow reductionist fashion. The panel's version of a 'comparative safety assessment' consists of a comparison only between basic molecular and chemical properties, focusing on the genetically engineered trait, as well as on selected agronomic and phenotypic characteristics of a GM food or plant with some of its non-GM counterparts. The phenotypic traits are restricted to those of direct commercial relevance to farmers and seed companies such as 'plant vigour, growth and development, morphology, yield, crop characteristics, pest and disease susceptibility and fertility' ([42], p. 10). This is an example of narrow scientific reductionism as a working premise for EFSA. This frame systematically excludes questions about ecological interactions-relational or interactional effects-with other organisms or populations of the kind that ecological perspectives would raise.

The GMO panel's chosen interpretation of what could count as a 'comparative safety assessment' might be scientifically, though not procedurally, legitimate if any physiological, toxicological or other types of risks could be reliably anticipated on the basis of the limited datasets it has chosen to require and include. However, the biochemical and agronomic data required by EFSA (see above $[17,42]$ ) have not been shown to provide a sufficient basis for predicting biological, toxicological or ecotoxicological consequences for ERA. Moreover, the EFSA panel's 'comparative safety assessment' precedes the 'risk assessment' step, thus, effectively serving as a filtering step that allows only those GMOs or parts of the GMOs as isolated components to proceed to the 'risk assessment' step that were not deemed 'safe' already at the initial step. This 'scientific' choice is also a framing choice, and has normative consequences. Moreover, the panel's interpretation of the particular data-sets that it requires for the determination of the 'comparative safety' has not been guided by any specific risk hypothesis or hypotheses which only follow after that.

The EFSA GMO Panel's approach in its 2010 guidance on environmental risk assessment of requiring and relying on 'comparative safety assessments' of chemical analyses and phenotypic characteristics to indicate whether or not any biological, toxicological, ecological risks could be anticipated, has depended upon a cluster of unrecognized RAP considerations of all three types; as does the inclusion of numerous unrelated control varieties into the comparison (see e.g., "Different concepts for risk assessment" section on unrelated reference controls). The panel's approach has narrowly restricted the scope and limits of what it has deemed as relevant risks, which data have been necessary and sufficient to support key decisions, and how those data were interpreted: favorably or unfavorably. EFSA's 2010 guidance document on environmental risk assessments of GMOs presumed several normatively based substantive, procedural and interpretative RAP judgements, but without any acknowledgement that this was an intrinsic constituent of the guidance it chose to provide. Instead of acknowledging that it was providing policy guidance (to itself), the document was a classic exercise in technocratic rhetoric, because it (mis)represented its chosen approach as if it relied purely on scientific and technical considerations. The only legitimate practice would have been to acknowledge the indispensable RAP judgements as irredeemably normative assumptions. These should have been properly subjected to the wider, inclusive policy deliberation which such normative choices deserve, and as the Codex Treaty recognizes.

If EFSA and its GMO panel had acted in accordance with the commitments that the European Commission made to Codex, then as a risk assessor, it would not have adopted a singular prescriptive approach as if it were purely scientific, rather it would have insisted, as a public matter, that the European Commission implement 
its commitments, as risk managers, to provide EFSA, as risk assessor, with comprehensive RAP guidance. In the absence of such RAP guidance from the Commission, EFSA should have confined its advice to setting out for the European Commission, for EU Member States and for all relevant stakeholder groups, what it believed was known, and what was uncertain, about the likely consequences of adopting, or failing to adopt, a range of alternative competing scientific approaches. Further, we suggest, EFSA should have identified which parts of the European Commission's mandate for GMO risk assessment required further normative direction from the (democratic) policy agent, which they as EFSA were not qualified to provide. In its role as risk manager, the Commission in consultation with all interested parties, should have chosen the approach that it wanted EFSA to follow, instead of leaving EFSA to take implicit responsibility for crucial policy judgements.

Our analysis of the EFSA panel's 2010 guidance document on environmental risk assessment reveals that EFSA's 'problem formulation' (i.e., framing, or part of the RAP input) step rests on models and concepts developed exclusively by biotechnology industry representatives and their scientific collaborators. Eight of the ten publications cited in support of EFSA's 'problem formulation' step, listed in footnote 11 on p. 15 [17], were authored or coauthored by scientists working for industry, together with collaborating scientists from public research institutions in the USA and the EU who agree with that particular interpretation. In contrast, EFSA ignored all publications that have proposed alternative models for problem formulation that would address a broader scientific range of possible risks, and consequently require data from more and different types of studies. These would also allow for the participation and deliberation on the part of a wider range of stakeholders [43-49] (see also the exchanges between Wynne and Wickson [50], and the EFSA GMO Panel, 2012, in EMBO Reports [51]).

An important feature of one of those alternative models is that it recommends a 'problem formulation' procedure not just to assess a single technological innovation in isolation, but rather to assess the choices between alternative technological options as well as clarifying the criteria by which those options should be judged. The team developed an approach that they termed 'Problem Formulation and Options Assessment' (PFOA), which, unlike the prevailing official EFSA EU process, would be consistent with the Codex RAP stipulation ([36] - see above). The authors have described the PFOA methodology as: "a science-based multi-stakeholder process to formulate problems and assess options as a basis for environmental risk assessment when a country is considering the introduction of a genetically modified organism
(GMO) into a specific environment." ([47], p. 65) (emphasis added).

PFOA is a framework that starts by identifying the key societal need(s) that the introduction of a GM crop variety into an agricultural system is expected to address. It compares the GM variety to other possible alternative technological pathways for meeting that societal need. Hence, a PFOA puts people and their needs at the center of its criteria of appraisal and then relies upon a transparent, inclusive process that should be informed by the best available scientific evidence and understanding. More importantly, it incorporates precaution as a fundamental guiding principle, which the EU is also formally committed to uphold. Furthermore, the PFOA approach, developed by international experts working independently of the agro-biotechnology industry, was tested with four real-world GMO case examples [52-55] and a handbook issued detailing the PFOA process for general use [48]. EFSA's approach does not include (or even acknowledge) any initial assessment of competing technological options as part of its 'comparative' approach. It opted instead straight for a model provided by the biotechnology industry that is directly contrary to the PFOA model, by virtue of the way it preemptively forecloses and excludes important normative questions and restricts its testing- and data-requirements, whilst also eliminating precaution from consideration.

In its 2012-2016 strategy document EFSA asserted that: "Since its inception, EFSA has...striven to work openly and transparently, relaying often complex scientific issues in a manner that is both accessible and useful to risk managers and other stakeholders. The Scientific Panels and the Scientific Committee have worked to ensure that scientific outputs clearly indicate what data or other information have been considered or disregarded and why, the nature and level of uncertainty, assumptions made; and any minority views that are held." ([56], 2012 p. 9). Published evidence shows those attractive EFSA claims to be untrue, at least for the GMO domain (see e.g., $[41,57,58])$.

\section{Re-introducing the concept of 'substantial equivalence' into EU risk assessment by renaming it a 'comparative safety assessment'}

The concept of the putative 'substantial equivalence' of GM foods to their non-GM counterparts has had a contested history (e.g., [59-61]). It was initially developed in the context of the US approach of not regulating foodstuffs derived from GMOs [62] and was later incorporated into a legally non-binding report by the OECD in 1993 [63]. This suggested that the safety of a new GM food could be assessed by comparing it with a similar traditional food that had been proven safe in 
normal use over time. This concept shares the distinctive assumption of the US permissive system that processes of genetic engineering will not cause greater unpredicted and/or unintended adverse effects than the application of conventional breeding methods and, therefore, can be expected to lead to no new risks or new types of risks. Consequently, the comparisons envisaged, for assessment purposes, can be limited to comparisons of biochemical analyses of basic plant compounds such as levels of proteins, carbohydrates, vitamins and minerals. It was subsequently also invoked by a joint FAO/WHO consultation on GM risk assessment (FAO/WHO 1996) [64].

The EU's legislation since 1990, however, implicitly contests that assumption; it stipulates that GM products must be scientifically tested and assessed for biological, toxicological and ecological risks, because GMOs cannot be assumed to be safe solely on the basis of data from chemical analyses and phenotypic characterization. Accordingly, in the late 1990s, the scientific legitimacy of that limited concept and the adequacy of its interpretation and employment for policy purposes were increasingly critically judged. The European Commission eventually proposed abandoning the concept, in part because it was pointed out that between 1985 and March 1996 the UK and European authorities had repeatedly assumed and asserted that BSE (or Mad Cow Disease) was 'substantially equivalent' to the familiar long-term sheep disease known as 'scrapie', and therefore posed no risk to human health [65]. That non-precautionary assumption had been proven wrong with devastating consequences for the affected humans.

In July 2001, the European Commission proposed a new 'Regulation on Genetically Modified Food and Feed' that said: "In order to ensure clarity, transparency and a harmonized framework for authorization of genetically modified food, this proposal does not include a notification (simplified) procedure as laid down in Regulation EC 258/97 on novel foods...which are substantially equivalent to existing foods." ([66], emphasis added). The draft regulation stipulated in paragraph 6 that: "In order to ensure clarity, transparency and a harmonised framework this notification procedures [...involving the attribution of substantial equivalence...] should be abandoned in respect of genetically modified foods." (op. cit. [66], para 6, p. 12, emphases added). As Levidow et al. [61] have argued, the concept of substantial equivalence was not abandoned, it was merely recast in a modified form and in a different vocabulary, namely in terms of a 'comparative approach'. Subsequently, it was re-adopted by the EFSA panel and phrased in terms of a 'comparative safety assessment'-along with the highly reductionistic interpretive norms as to what level and kind of comparison was deemed scientifically adequate in this context (see above). This EFSA reincorporation was not acknowledged as such, and also (mis)represented as if a solely technical question, as criticized above.

The suggestion that the concept of substantial equivalence can be used as a 'safety assessment', or, at least, as grounds for not requiring safety tests, was explicitly rejected in the final 2003 EU legislation, despite EFSA's unannounced use of its equivalent, the 'comparative safety assessment'. The Preambular Recital 6 of the final EU Regulation 1829/2003 mentions that the now obsolete "Regulation (EC) No 258/97 also provides for a notification procedure for novel foods which are substantially equivalent to existing foods. ... (This) procedure should be abandoned in respect of genetically modified foods." [67].

While Codex proposed using the concept of substantial equivalence as a point of departure for a risk assessment of GM foods [68], an analogous step was not taken in another international environmental risk assessment for GMOs. Notably, the Report of the Ad Hoc Technical Expert Group on Risk Assessment and Risk Management under the Cartagena Protocol [69] and the respective decision of the Eighth Meeting of the Parties to the Cartagena Protocol on a 'Roadmap' for risk assessment ([69], p. 19), gave no indication that a 'comparative safety' assessment should be a new step or even an assumed question in environmental risk assessment. As explained above, the concept of a 'comparative safety assessment' was invoked solely on the initiative of the EFSA GMO panel, which used it as a preliminary filter to a risk assessment, and to circumscribe its scope. This very significant alteration to EU regulatory policy, misrepresented as if "expert guidance", went far beyond the limits of scientific advice; it introduced a policy device that effectively undermines the comprehensiveness of environmental risk assessments that the legislation requires. This was not called for by the European Commission-nor by any other body.

EFSA's 2010 guidance on the assessment of GM plants said: "Comparative safety assessment includes molecular characterisation, the agronomic and phenotypic characteristics of the GM plant in question, as well as its compositional analysis...." ([17], emphases added). EFSA's 2011 guidance on GM food and feed risk assessment [17] elaborated further that: "The underlying assumption of this comparative approach is that traditionally cultivated crops have a history of safe use for consumers and/or domesticated animals. These traditionally cultivated crops can thus serve as comparators when assessing the safety of GM plants and derived food and feed. The application of this comparative risk assessment in the area of plant composition (Kok and Kuiper, 2003), also denoted as the concept of substantial equivalence (FAO/WHO, 2000; OECD, 1993), serves the 
purpose of identifying intended and unintended differences and/or lack of equivalences between GM plants and derived food and feed and their comparator(s), taking into account the range of natural variation." (emphases added).

The EFSA panel has subsequently used this 'comparative (safety) assessment' step for GM plants and GM food and feed, as an opportunity to declare the many reported statistically significant differences found among the chemical analytical data (called 'compositional analyses' or 'comparative analyses of the composition') to be 'not biological relevant', so long as the reported values fall within the 'natural variation' of 'traditionally cultivated crops', i.e., data derived from any non-GM varieties ever analyzed in history as long as they may share common pedigree (e.g., [70-72]): "The potential variability in the degree of genetic similarity between the GM plant and its comparator(s) does not necessarily compromise the reliability of the safety assessment, provided that the comparator is genetically "as close as possible" to the GM plant with regard to its breeding pedigree." [17].

In addition, analogous basic data on agronomic, phenotypic performance of the GM crop should be submitted to document that the product's efficacy and agronomic performance (e.g., plant vigor, growth, yield, etc.) is 'substantially' equivalent to the non-GM variety as compared to their chosen comparators including references and controls. While this information is useful to begin a risk assessment, EC Regulation 1823/2003 states clearly that it is not in any way to be treated as a 'safety' assessment in its own right which the EFSA term comparative 'safety assessment' claims (see quote above). Moreover, the nonGM natural ranges chosen by applicants and accepted by the EFSA GMO panel are so broad as to make 'significant difference' almost beyond detection. Again, an apparently purely scientific determination carries strong normative framing commitments-from EFSA-which relax ab initio any risk assessment performed within them. We explain this next.

\section{Including unrelated reference 'controls'}

Paradoxically, the use of unrelated and even historical data from non-GM varieties of the GMO is one remarkably open-ended aspect to be assessed by applicants in the compositional analyses of the comparative safety assessment. And it is another example of introducing uncalled-for changes to the EU's stipulations. Contrary to the EFSA GMO panel claims (see above), this does serve to 'maximize' the variability in the data to constitute what is deemed to be a gratuitously diverse 'control group', to which GM plants (their compositional characteristics) are compared. Firstly, it introduces substantial quantities of data for 'controls' in contrast to the far fewer data provided for GM varieties. Secondly, the permissible levels of variability (granted by forgiving 'limits of concern'; [73]) within the selected non-GM counterparts) is so great as to generate considerable 'statistical noise' in the control data-set that are entirely unrelated to the question at issue. This makes it much less likely that statistically significant differences between the GM and conventional plant compounds would be identifiable, even if there are such differences between the GM variety and the varieties from which it was derived. This EFSA choice does undoubtedly 'compromise the reliability of the safety assessment' (see quote above), in a direction favoring a 'scientific' determination of 'no harm.'

The extraneous noise added to the control group can mask many differences between a GMO and the particular varieties from which it was derived; it diminishes the sensitivity of the test, rather than increasing it. The lack of statistically significant differences in turn, however, is then deemed by the EFSA panel sufficient to declare the new GM plant comparatively as safe as the non-GM counterparts. But even if significant differences between the measured biochemical compounds are reported that also regularly exceed even historical ranges, these differences are interpreted away as being biologically irrelevant (e.g., see case examples [70-73]).

According to EU Directive 2001/18 and the Cartagena Protocol on Biosafety, the varieties from which a GMO was derived (near isogenic parent) are the relevant comparator and the only scientifically valid and precise control that could indicate differences that could be scientifically attributed to the genetic modification process. Nevertheless, the EFSA GMO panel has unilaterally chosen to accept far more 'noise' into the comparator data. Widening the variability in the set of comparators to contextualize the assessment in 'natural variation... estimated from a set of non-GM reference varieties' [15] is neither required by the EU Regulation nor is it scientifically justified, necessary or appropriate for a sound safety and risk assessment process. To the extent that comparisons may be revealing, the focus should be between the novel GM variety and the parent varieties from which it was derived, not with any other remotely related or antecedent varieties. Adding more varieties for broader comparison would only make sense scientifically for risk assessment of GMOs, if they would also all be available as both GM and non-GM variety. In any case, such comparisons can be interpreted in opportunistic or inconsistent ways as there are very permissive and flexible 'limits of concern' above or below which variations of those parameters, compared to a parental organism, are considered not to be substantially equivalent [73].

In practice, commercial applicants have been allowed to choose the comparators that suit them. But such 
choices have clear policy-implications, and if they were decided in accordance with the provisions of the Codex agreement on RAP, the parameters for choosing should be set by (accountable) risk managers in DG-Sante at the European Commission, and not by EFSA, and certainly not by private industrial or commercial applicants (Wickson and Wynne [51] incl. related correspondences). But instead, this has provided applicants with considerable freedom to select and to weaken the benchmarks against which their products are to be officially judged. That 'scientific' tactic substantially prioritizes commercial interests over the protection of environmental and public health and is neither objective, independent nor scientific, it is the antithesis of precaution. It undermines the democratic EU policy commitments it is supposed to support.

\section{The consequences of EFSA's reductionist strategy}

Once 'comparative safety' has been formally declared, it is invoked by EFSA's GMO panel to narrow, or reduce, the evaluation in the subsequent risk assessment to only the GM-inserted chemical compound 'coded' for by the genetic modification, e.g., the isolated Bt toxin in case of GM Bt crop plants [74, 75]. Underlying this approach is a reductionistic conceptual understanding of biology, genetics and ecology. In this, EFSA's GMO panel aligns closely with US regulators in that both assume that each genetic change, and each added gene, acts independently of any and all other genes or changes; it is therefore a resolutely reductionist approach. Moreover, it shows no sign of interest in being open-as it claims to be-to more comprehensive scientific framings of the risk assessment question, nor to established scientific paradigms which reflect those. EFSA's GMO panel assumes that if a new transgene-'coded' product (e.g., Bt toxin) with a pre-determined level of risk is added to an organism, the overall risk level of that newly created GM organism will only be increased by that level and kind of risk arising from the newly added transgene. In effect, it is assuming that the (new) whole is only the 'sum of its (new and old) parts', ignoring all newly created interactional relations. It fails to acknowledge the widely accepted scientific understanding that genes can and do interact, not only amongst themselves in the genome, but also with other intracellular, intra-organismic, and environmental factors, and often do so in non-additive and (so far) unpredictable ways (e.g., [76, 77]). Such possible effects are excluded for example by the reductionist scientific method of testing only the purified Bt toxin coded for by the inserted gene, rather than the full GM plant, which needs to be tested for the effects also of those further whole cell, whole organism, and organism-environment interactions, some of which may be uncontrolled and unknown, thus overlooked by the existing dogma. Again, a set of non-precautionary strategic scientific commitments with normative consequences for policy have been made by EFSA, despite the EU's ostensible policy, indeed, Treaty commitment to the Precautionary Principle.

Consequently, risk assessments using this approach may not require the safety testing of the GMO at all, or may allow stopping short of that by accepting a few, basic studies using the 'coded' transgene product isolated from GM microbes instead of the GM plant [74-76, 79]. This novel substance is then treated only as an 'added' chemical compound and tested in isolation from the actual subject of regulations, the GM plant. Since the Bt toxin is a pesticidal compound, it is tested like a synthetic pesticide following prescribed OECD first-tier testing protocols. The pesticide-testing regime is based on the use of universal surrogate testing species, many of which have little if any ecological relevance to any receiving agro-ecological environment. The protocols are narrowly designed to test direct, immediate and acutely toxic effects of the purified substance produced and extracted from bacteria (not from the GM plants) as an isolated single product. Consequently, what is a living organism, distributing and reproducing itself in variable open environments, is assessed as if it were only a pure pesticidal chemicaleffectively reducing biology and ecology to chemistry $[75$, 79].

Similarly, for herbicide-tolerant (HT) GM plants, while the GM HT plant is sold and its benefits are assessed solely as an integrated package of the GM plant with the corresponding herbicide, for risk assessment purposes, that integrated package is reduced to at least four components presumed to operate in isolation as the sum of those parts: the GM plant is declared substantially equivalent as described above. The GM trait in the case of Roundup-tolerant GM plants is the substitute EPSP synthase. ${ }^{1}$ The corresponding herbicide is not considered a part of the GMO technology (although it is the fundamental part of the GMO technology for sales, uses, benefits and patent purposes), and is thus assessed by separate pesticide regulations [74, 75, 78, 80-82]. Lastly, the herbicide itself is further reduced to its declared active principle and 'adjuvants' (Fig. 1).

Consequently, herbicide-residues contained in GM HT crops were ignored and not tested for regulatory risk assessment of GM crops and, today, after mounting pressure, are tested for GM HT plants but in unrealistically low concentrations $([58,78,80,81])$. Detailed critiques

\footnotetext{
${ }^{1}$ A slightly different enzyme from a microbe which is allowing the GM plant when sprayed with Roundup (which blocks the plant-native EPSP synthase) to continue the biosynthesis of certain aromatic amino acids (phenylalanine, tyrosine, tryptophan) via the shikimate pathway.
} 


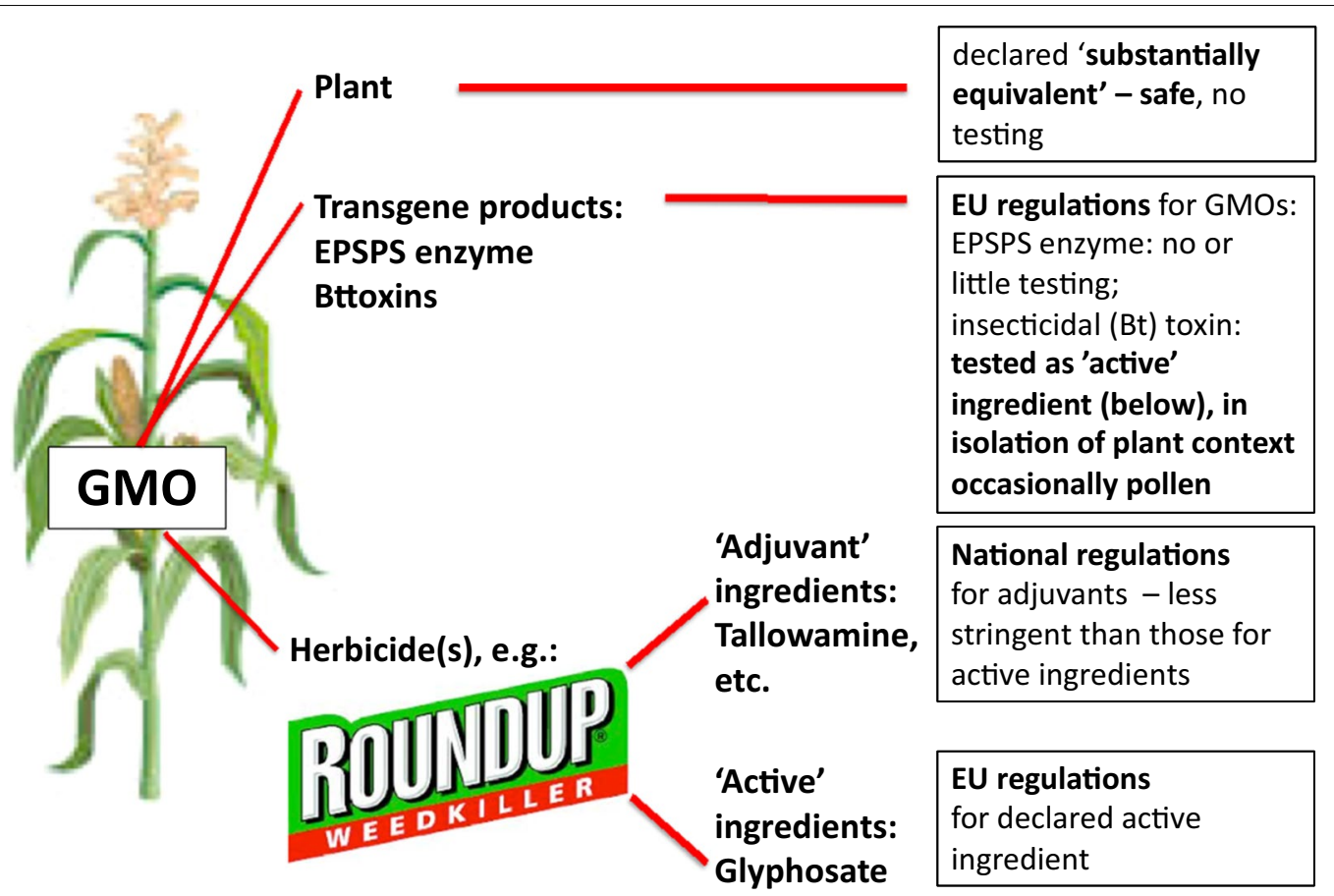

Fig. 1 Reductionism in the environmental risk assessment of GM crops (e.g., HT and Bt): GM HT Bt plant package divided into individual components, assessed in isolation from each other under different national and EU regulations

of this reductionistic approach to evaluating the safety of GMOs-and by implication also of pesticides-have been published in the scientific literature (e.g., [75, 78-82]).

\section{Conclusions on EFSA Guidance on ERA of GM plants}

The assumption that 'familiarity' or 'substantial equivalence' of a part of an organism indicates 'safety' contravenes the intention, spirit and wording of the EU legislation and has vanishingly little scientific evidential support. At best, it could be characterized as a hypothesis that could and should be tested. But the EFSA GMO Panel uses it as grounds for exempting GMOs from testing. By creating an incentive not to require or conduct further tests, EFSA's guidance is, in this respect, not just unscientific but anti-scientific.

While EU legislation assumes that processes of genetic engineering can potentially cause different and potentially more unpredictable and unintended adverse effects than the application of conventional breeding methods, EFSA instead assumes, without EU legislative authorization, that the molecular-level changes assumed to be controllably and precisely engineered into a GMO may be individually and separately identified by chemical analyses, and assessed on the basis of those chemical data. But biological activity, toxicological potency and ecological interactions cannot be identified or characterized solely by reference to the results of crude (or even sophisticated) chemical analyses alone.

Consequently, much of the EFSA GMO panel's RA Guidance reads rather like a guidance on 'how to minimize' or even avoid providing meaningful data: by encouraging commercial applicants to substitute for experimental testing of actual GM plants; by relying on desk exercises based on untested theoretical and hypothetical considerations; and with some testing of artificially isolated add-on compounds 'coded' by the transgenes, but not extracted from the GMO to be regulated (except for the occasional low-expressing pollen test). Much of this may have little or no relevance to realworld ecological and human health contexts.

EFSA's mandate from the Commission was to develop guidance to implement the EU's GMO legislation. It was not to alter and steer the approach fundamentally away from those aims, nor to harmonize it with the US approach. EU legislation stipulates that each GMO has to be assessed through a risk assessment without a preceding upstream screening and decision-making process. No provision in the text of Directive 2001/18 or Regulation $1829 / 2003$ justifies or requires the introduction of a 'comparative (safety) analysis'. It is the GM Organism that should be assessed, not just the isolated, biochemical difference between it and some non-GM comparators. Directive 2001/18/EC defines the principles of 
environmental risk assessments as the precautionary principle plus five other principles. Nobody has tasked, entitled or asked EFSA to add the comparative safety assessment as a general principle for the risk assessment of GM plants' [17], emphasis added).

The EFSA GMO panel has contrived to exempt novel GM organisms from proper empirical testing and assessment, weakening its ability to protect against potential unintended adverse effects caused by the genetic modification processes. For the industry, this has the advantage that much or all of the same submitted data for regulatory decision are accepted on both sides of the Atlantic, despite their supposed-and to Europeans reassuringdifferences of principle. However, general potential risks that the panel fails to assess continue to be borne by the environment, consumers and society at large.

The problems highlighted in this paper indicate that substantial changes are required both at EFSA and in the European Commission, and in their interactions. At a minimum, the Commission should properly research, understand, and then deliver on the commitments concerning explicitly articulating risk assessment policies, in advance of risk assessments, and in accordance with the inclusive and accountable procedure stipulated in the Codex provisions on risk assessment policy-making. It should have done this some years ago. EFSA and its expert panels probably needs to undergo a similarly urgent process of learning, so that its panels can then make clear how those risk assessment policies frame and influence the substance, procedure and outcomes of their 'scientific' deliberations. In accordance with international agreements to which the EU and every one of its memberstates is a signatory, such as Codex, we are recommending changes not just to the risk assessment policies, but also to the institutional location at which, and to the processes by which, those policy issues are decided. Just as it is illegitimate to allow policy actors to make scientific judgements, so too is it illegitimate to allow supposedly scientific actors (i.e., EFSA) to decide policy questions. It is even more problematic to misrepresent those judgements as if they were purely scientific. The process by which the Commission decides GMO risk assessment policies for EFSA should ensure that they do so 'in consultation with risk assessors and all other interested parties' which includes elected European Parliament members, and civil society and its variety of representatives.

If this unacknowledged policy burden buried within what is called 'science' were to be removed from EFSA, perhaps it could then better ensure that its framing procedures and subsequent risk assessments meet the criteria of being systematic, complete, unbiased (which would include being open to peer-review), and transparent. Then we might also further discover two major all-round benefits: that EFSA's science is able to support and comply with EU democratic legislative and regulatory objectives, rather than to undermine them; and that EFSA's repeated failure to achieve European public and Parliamentary respect $[83,84]$ might begin to reverse itself.

\begin{abstract}
Abbreviations
GM(O): Genetically modified (organism); LMO: Living modified organism (synonymous to GMO); EFSA: European Food Safety Authority; EU: European Union; US: United States (of America); NIH: US National Institute of Health; ERA: Environmental risk assessment; RAP: Risk assessment policy; DG: Directorate General (of the EU Commission); PFOA: Problem formulation and option assessment; FDA: US Food and Drug Administration; OECD: Organisation for Economic Co-operation and Development; $\mathrm{HT}$ : Herbicide tolerant (GM plants that are made resistant to herbicides); Bt: Bacillus thuringiensis (GM plants that express a toxin from this bacillus); EPSP: 5-Enolpyruvylshikimate-3-phosphate.
\end{abstract}

\section{Acknowledgements}

We thank two anonymous reviewers for their detailed and valuable comments.

\section{Authors' contributions}

$\mathrm{AH}$ and $\mathrm{HM}$ conceived the review and compiled and analysed the relevant documents and materials for review on risk assessment, EU regulations and EFSA guidances. EM and BW compiled and analysed the relevant documents on risk assessment policies, Codex and FAO/WHO documents. All authors contributed their personal experience in decades of debates and interactions with all mentioned involved government and international bodies. AH prepared the first version of the manuscript and finalized it with contributions from all other authors. Finally, all authors critically reviewed the document and agreed on the submitted version. All authors read and approved the final manuscript.

\section{Funding}

No specific funds for this work were received.

\section{Availability of data and materials}

Not applicable-all mentioned materials are available online and cited properly.

\section{Ethics approval and consent to participate}

Not applicable.

\section{Consent for publication}

Not applicable.

\section{Competing interests}

None of the authors has any competing interests.

\section{Author details}

1 Swiss Federal Institute of Technology, Institute of Integrative Biology, Zurich, Switzerland. ${ }^{2}$ European Network of Scientists for Social and Environmental Responsibility (ENSSER), Berlin, Germany. ${ }^{3}$ Lancaster University, Lancaster, UK. ${ }^{4}$ Science Policy Research Unit, University of Sussex, Brighton, UK.

Received: 22 November 2019 Accepted: 7 March 2020

Published online: 03 April 2020

References

1. Wynne BE (1989) Frameworks of rationality in risk management: towards the testing of naïve sociology. In: Brown J (ed) Environmental threats: perception, analysis, management. Belhaven Press, London, pp 47-69

2. Codex (2007) Report of the Codex Twenty-Fourth Session of the Codex Committee on General Principles, Paris, France, 2-6 April 2007 to the Codex Alimentarius Commission, Thirtieth Session, Rome, Italy, 2-7 July 2007. http://www.codexalimentarius.net/download/report/681/ al30 33e.pdf. Accessed 15 Nov 2018 
3. Millstone E, van Zwanenberg P, Levidow L, Spök A, Hirakawa H, Matsuo M (2008) Risk-assessment policies: differences across jurisdictions. Institute for Prospective Technological Studies, Seville, Spain, EUR Number: 23259 EN, April 2008

4. Cohen SN (1975) The manipulation of genes. Sci Am 233:25-32

5. Cohen SN (1977) Recombinant DNA: fact and fiction. Science 195:654-657

6. Watson JD (1977) An imaginary monster. Bull At Sci 33:19-20

7. Watson JD (1977) Remarks on recombinant DNA. CoEvol Quart Summer 197:40-41

8. Wright S (1994) Molecular politics. Developing American and British regulatory policy for genetic engineering, 1972-1982. The University of Chicago Press, Chicago

9. Marden E (2003) Risk and regulation: US regulatory policy on genetically modified food and agriculture, 44 B.C.L. Rev. 733

10. May R (1999) Chief Scientific Advisor UK Government. Is GM safe? http:// www.bbc.co.uk/science/horizon/1999/gmfood_script.shtml. BBC Interview, Accessed 27 Feb 2020

11. Borlaug NE (2000) Ending world hunger. The promise of biotechnology and the threat of antiscience zealotry. Plant Physiol 124:487-490

12. Court of Justice of the European Union (2018) Organisms obtained by mutagenesis are GMOs and are, in principle, subject to the obligations laid down by the GMO Directive. PressRelease. https://curia.europa.eu/ jcms/upload/docs/application/pdf/2018-07/cp180111en.pdf; http://curia .europa.eu/juris/documents.js?num=C-528/16. Accessed 25 July 2018

13. Gelinsky E, Hilbeck A (2018) European Court of Justice ruling regarding new genetic engineering methods scientifically justified: a commentary on the biased reporting about the recent ruling. Environ Sci Eur 30:52. https://doi.org/10.1186/s12302-018-0182-9

14. NRC (National Research Council) (1983) Risk assessment in the federal government: managing the process. National Academies Press, Washington, DC

15. Suter GW (1993) Ecological risk assessment. Lewis Publishers, Boca Raton

16. EEC (1990) Directive 90/220/EEC on the deliberate release into the environment of genetically modified organisms. Off J L 117:0015-0027

17. EFSA (2010) Guidance on the environmental risk assessment of genetically modified plants. EFSA J 8(11):1879. https://doi.org/10.2903/j. efsa.2010.1879

18. EFSA (2011) Guidance for risk assessment of food and feed from genetically modified plants. EFSA J 9:2150. https://doi.org/10.2903/j. efsa.2011.2015

19. Commandeur P, Joly PB, Levidow L, Tappeser B, Terragni F (1996) Public debate and regulation of biotechnology in Europe. Biotech Dev Monit 26:2-9

20. Toft J (2000) Denmark: potential polarization or consensus? J Risk Res 3:227-235

21. Dreyer M, Gill B (2000) Germany: continued elite precaution along side continued public opposition. J Risk R 3:219-226

22. EU Directive 2001/18, Directive 2001/18/EC of the European Parliament and of the Council, On the deliberate release into the environment of genetically modified organisms and repealing Council Directive 90/220/ EEC' Official Journal of the European Communities L 106/1-38, 17.4.2001

23. Secretariat of the Convention on Biological Diversity (2000) Cartagena protocol on biosafety to the convention on biological diversity-text and annexes. http://bch.cbd.int/protocol/

24. Secretariat of the Convention on Biological Diversity (2012) Guidance on risk assessment of living modified organisms. http://bch.cbd.int/proto col/guidance_risk_assessment

25. UNEP (United Nations Environmental Programme) (2010) Final report of the Ad Hoc Technical Expert Group on risk assessment and risk management under the Cartagena Protocol on Biosafety. Document id: UNEP/ CBD/BS/COP-MOP/5/INF/12 24 July 2010. http://www.cbd.int/doc/meeti ngs/bs/mop-05/information/mop-05-inf-12-en.pdf

26. UN CBD MOP 5 Decision BS-V/12 risk assessment and risk management (Articles 15 and 16). http://www.cbd.int/decision/mop/?id=12325

27. Martineau B (2019) Gene editing's extra DNA problem: Déjà vue all over again. A commentary on Norris et al. 2019. https://biotechsal on.com/2019/09/06/gene-editings-extra-dna-problem-deja-vu-all-overagain/
28. Norris AE, Lee SS, Greenlees KJ, Tadesse DA, Miller MF, Lombardi H (2019) Template plasmid integration in germline genome-edited cattle. bioRxiv preprint first posted online. https://doi.org/10.1101/715482

29. Wilson A (2017) Goodbye to golden rice? GM trait leads to drastic yield loss and "metabolic meltdown. Independent Science News September 2017 a commentary on Bollinedi et al. 2017

30. Bollinedi H, Prabhu KV, Singh NK, Mishra S, Khurana JP, Singh AK (2017) Molecular and functional characterization of GR2-R1 event based backcross derived lines of Golden Rice in the genetic background of a mega rice variety Swarna. PLoS ONE 12(1):e0169600

31. Cassels AC, Curry RF (2001) Oxidative stress and physiological, epigenetic and genetic variability in plant tissue culture: implications for micropropagators and genetic engineers. Plant Cell Tissue Organ Cult 64:145-157. https://doi.org/10.1023/A:1010692104861

32. Regal PJ (1994) Scientific principles for ecologically based risk assessment of transgenic organisms. Mol Ecol 3:5-13

33. Latham JR, Wilson AK, Steinbrecher RA (2006) The mutational consequences of plant transformation. J Biomed Biotechnol. https://doi. org/10.1155/JBB/2006/25376

34. Eckerstorfer MF, Engelhard M, Heissenberger A, Simon S, Teichmann $H$ (2019) Plants developed by new genetic modification techniquescomparison of existing regulatory frameworks in the EU and non-EU countries. Front Bioeng Biotechnol 7:26. https://doi.org/10.3389/fbioe 2019.00026

35. Food and Water Watch (2005) Biotech ambassadors-How the US State Department Promotes the Seed Industry's Global Agenda. https://www. foodandwaterwatch.org/sites/default/files/Biotech\%20Ambassadors\%20 Report\%20May\%202013.pdf

36. An example of US pressure tactics on EU regarding genetically engineered crops-Wikileaks Cable. https://wikileaks.org/plusd/cables/07PAR IS4723 a.html. Accessed 31 Jan 2020

37. Ventura J (2011) Embassy cables_-America's fight against Europe over biotech crops. In: 63 Documents the government does not want you to read

38. Corporate Europe Observatory (2019) US pressure on EU to de-regulate new GM. https://corporateeurope.org/en/2019/07/us-pressure-eu-deregulate-new-gm; https://corporateeurope.org/sites/default/files/201907/Meeting\%20Andriukaitis\%20McKinney.pdf

39. Url B (2018) Don't attack science agencies for political gain. Nature 553:381

40. Millstone E, Dawson E (2019) EFSA's toxicological assessment of aspartame: was it even-handedly trying to identify possible unreliable positives and unreliable negatives? Arch Public Health. https://doi.org/10.1186/ s13690-019-0355-z

41. Chvátalová V (2019) A critical evaluation of EFSA's environmental risk assessment of genetically modified maize MON810 for honeybees and earthworms. Environ Sci Eur 31:52

42. EFSA Gmo Panel (EFSA Panel on Genetically Modified Organisms) (2015) Guidance on the agronomic and phenotypic characterisation of genetically modified plants. EFSA J 13(6):4128. https://doi.org/10.2903/j. efsa.2015.4128

43. Millstone $\mathrm{E}$ (2009) Science, risk and governance: radical rhetorics and the realities of reform in food safety governance. Res Policy 38:624-636. https ://doi.org/10.1016/j.respol.2009.01.012

44. Nelson KC, Kibata G, Muhammad L, Okuro JO, Muyekho F, Odindo M, Ely A, Waquil J (2004) Chapter 3. Problem formulation and options assessment (PFOA) for genetically modified organisms: The Kenya Case Study. In: Hilbeck A, Andow DA (eds) Environmental risk assessment of genetically modified organisms, vol 1. A case study of Bt maize in Kenya. Cabi Publishing, Wallingford

45. Capalbo DMF, Simon MF, Nodari RO, Valle S, dos Santos RF, Coradin L, de Duarte JO, Miranda JE, Dias EPF, Quang QL, Underwood E, Nelson KC (2006) Consideration of problem formulation and option assessment for Bt cotton in Brazil. In: Hilbeck A, Andow DA, Fontes EMG (eds) Environmental risk assessment of genetically modified organisms, vol 2. Methodologies for assessing Bt cotton in Brazil. CABI Publishing, Wallingford

46. Nelson KC, Basiao Z, Cooper A, Dey M, Lorenzo H, Kunawasen S, Sifa L, Fonticiella D, Ratner BD, Toledo MI, Leelapatra W (2006) Problem formulation and options assessment (PFOA): science-driven deliberation in risk assessment of transgenic fish. In: Kapuscinski AR, Hayes KR, Li S, Dana G 
(eds) Environmental risk assessment of genetically modified organisms, vol 3. Methodologies for transgenic fish. CABI Publishing, Wallingford

47. van Uyen Nguyen, van Chi Nguyen, van Bo Nguyen, Sat Le Minh, Nhan Hoang Thanh, Hong Nguyen Xuan, Quyen Le Quang, Nhan Sat Hoang Thanh, Hong Nguyen Xuan, Quyen Le Quang, Wals A, Capalbo DMF, Nelson KC (2008) Consideration of problem formulation and option assessment for Bt cotton in Vietnam. In: Andow DA, Hilbeck A, Nguyen VT (eds) Environmental risk assessment of genetically modified organisms, vol 4. Challenges and opportunities with Bt cotton in Vietnam. Cabi Publishing, Wallingford

48. Nelson KC, Banker MJ (2007) Problem formulation and options assessment handbook. University of Minnesota, St. Paul. http://www.gmoer a.umn.edu/public/publications/index.html

49. US EPA (2009) Committee on improving risk analysis approaches used by the U.S. EPA 2009. Science and decisions: advancing risk assessment. National Research Council, Washington, DC. http://www.nap.edu/catal og.php?record_id $=12209$

50. Wynne B, Wickson F (2012) Reply to J.N. Perry et al. EMBO Rep 13:482-483. https://doi.org/10.1038/embor.2012.71; Correspondence (June 2012) associated with the Science \& Society (February 2012) Correspondence

51. Wickson F, Wynne B (2012) The anglerfish deception. The light of proposed reform in the regulation of GM crops hides underlying problems in EU science and governance. EMBO Rep 13:100-105

52. Hilbeck A, Andow DA (2004) Environmental risk assessment of genetically modified organisms, vol 1. A case study of Bt maize in Kenya. Cabi Publishing, Wallingford

53. Hilbeck A, Andow DA, Fontes EMG (2006) Environmental risk assessment of genetically modified organisms, vol 2. Methodologies for assessing Bt cotton in Brazil. Cabi Publishing, Wallingford

54. Andow DA, Hilbeck A, Nguyen VT (eds) (2008) Environmental risk assessment of genetically modified organisms, vol 4. Challenges and opportunities with Bt cotton in Vietnam. Cabi Publishing, Wallingford

55. Kapuscinski AR, Hayes KR, Li S, Dana G (2007) Environmental risk assessment of genetically modified organisms, vol 3. Methodologies for transgenic fish. CABI Publishing, Wallingford

56. EFSA (2012) Science strategy of the European Food Safety Authority for 2012-2016. http://www.efsa.europa.eu/sites/default/files/corpo rate_publications/files/sciencestrategy 12.pdf

57. Bohn T (2018) Criticism of EFSA's scientific opinion on combinatorial effects of 'stacked' GM plants. Food Chem Toxicol 111:268-274. https:// doi.org/10.1016/j.fct.2017.11.023

58. Cuhra M (2015) Review of GMO safety assessment studies: glyphosate residues in Roundup Ready crops is an ignored issue. Environ Sci Eur 27:20-33

59. Millstone E, Brunner E, Mayer S (1999) Beyond 'substantial equivalence'. Nature 40:525-526

60. Millstone $E$ (2002) The limitations and potential utility of substantial equivalence. In: Evaluating substantial equivalence: a step towards improving the risk/safety evaluation of GMOs, Austrian Federal Environment Agency, Conference papers, vol 32. Vienna, pp 32-41

61. Levidow L, Murphy J, Carr S (2007) Recasting "substantial equivalence": transatlantic governance of GM Food. Sci Technol Hum Values. https:// doi.org/10.1177/0162243906293885

62. FDA (1992) Statement of policy: foods derived from new plant varieties: notice. Federal Register 57:22984-23005. http://www.fda.gov/Food/ GuidanceComplianceRegulatoryInformation/GuidanceDocuments/Biote chnology/ucm096095.htm

63. OECD (1993) Safety evaluation of foods derived by modern biotechnology: concepts and principles. Organisation for Economic Cooperation and Development, Paris

64. FAO/WHO (1996) Joint FAO/WHO Expert Consultation on Biotechnology and Food Safety, Rome, Italy, 30 September to 4 October 1996. http:// www.fao.org/ag/agn/food/pdf/biotechnology.pdf

65. van Zwanenberg P, Millstone E (2005) BSE: risk, science and governance. Oxford University Press, Oxford

66. European Commission (2001) Proposal for a regulation on genetically modified food and feed, 25 July 2001, p 7

67. European Commission (2003) Regulation (EC) No 1829/2003 of the European Parliament and of the Council of 22 September 2003 on genetically modified food and feed. Official Journal L 268, 18/10/2003, pp 0001-0022
68. Codex Alimentarius Commission (2003) Guideline for the conduct of food safety assessment of foods derived from recombinant-DNA plants. Food and Agriculture Organization, Rome

69. Cartagena Protocol on Biosafety to the Convention on Biological Diversity (2016) Report of the AHTEG on Risk Assessment and Risk Management under the Cartagena Protocol on Biosafety. Eighth Meeting of the Parties, Cancun, Mexico 4-17 December 2016-UNEP/CBD/BS/COP-MOP/8/ INF/3

70. EFSA (2007) Opinion of the Scientific Panel on Genetically Modified Organisms on an application (Reference EFSA-GMO-NL-2005-12) for the placing on the market of insect-resistant genetically modified maize 59122, for food and feed uses, import and processing under regulation (EC) No 1829/2003, from Pioneer Hi-Bred International, Inc. and Mycogen Seeds, c/o Dow Agrosciences LLC. EFSA J 470:1-25

71. EFSA (2013) Scientific Opinion on an application from Pioneer Hi-Bred International and Dow AgroSciences LLC (EFSA-GMO-NL-2005-23) for placing on the market of genetically modified maize 59122 for food and feed uses, import, processing and cultivation under Regulation (EC) No 1829/2003. EFSA J 11(3):3135. https://doi.org/10.2903/j.efsa.2013.3135

72. EFSA (2011) Scientific opinion on application (EFSA-GMO-CZ-2008-54) for placing on the market of genetically modified insect resistant and herbicide tolerant maize MON 88017 for cultivation under regulation (EC) No 1829/2003 from Monsanto. EFSA J 9(1 1):2428. https://doi.org/10.2903/j. efsa.2011.2428

73. Dolezel M, Miklau M, Heissenberger A, Reichenbecher W (2017) Are limits of concern a useful concept to improve the environmental risk assessment of GM plants? Environ Sci Eur 29:7

74. Hilbeck A, Defarge N, Lebrecht T, Bøhn TH (2020) Risk assessment of genetically engineered organisms in the EU and Switzerland (RAGES) Subreport: Insecticidal Bt crops-EFSA's risk assessment approach for GM Bt plants fails by design. https://www.testbiotech.org/en/content/rages -subreport-insecticidal-bt-crops

75. Hilbeck A, Meier M, Römbke J, Jänsch S, Teichmann H, Tappeser B (2011) Environmental risk assessment of genetically modified plants - concepts and controversies. Environ Sci Eur 23:13

76. Latham J, Love M, Hilbeck A (2017) The structure and functions of natural Bacillus thuringiensis insecticidal proteins in relation to risk assessment of GM Bt crops. Biotechnol Genet Eng Rev 33:62-96

77. Phillips PC (2008) Epistasis-the essential role of gene interactions in the structure and evolution of genetic systems. Nat Rev Genet 9:855-867

78. Bohn T, Cuhra M, Traavik T, Sanden M, Fagan J, Primicerio R (2014) Compositional differences in soybeans on the market: glyphosate accumulates in Roundup Ready GM soybeans. Food Chem 153:207-215. https://doi. org/10.1016/j.foodchem.2013.12.054

79. Dolezel M, Miklau M, Hilbeck A, Otto M, Eckerstorfer M, Heissenberger A, Tappeser B, Gaugitsch H (2011) Scrutinizing the current practice of the environmental risk assessment of GM maize applications for cultivation in the EU. Environ Sci Eur 23:33

80. Cuhra M, Bohn T, Cuhra P (2016) Glyphosate: too much of a good thing? Front Environ Sci 4:28. https://doi.org/10.3389/fenvs.2016.00028

81. Miyazaki J, Bauer-Panskus A, Bøhn T, Reichenbecher W, Then C (2019) Insufficient risk assessment of herbicide tolerant genetically engineered soybeans intended for import into the EU. Environ Sci Eur 31(1):92

82. Andow DA, Hilbeck A (2004) Science-based risk assessment for nontarget effects of transgenic crops. Bioscience 54:637-649

83. European Union Parliament Report on discharge in respect of the implementation of the budget of the European Food Safety Authority for the financial year 2015. A8-0098/2017. https://www.europarl.europa.eu/ doceo/document/A-8-2017-0098_EN.html?redirect

84. Corporate Europe Observatory (2017) EU parliament urges Food Safety Authority to finally cut industry ties. https://corporateeurope.org/en/ pressreleases/2017/04/eu-parliament-urges-food-safety-authority-final ly-cut-industry-ties

\section{Publisher's Note}

Springer Nature remains neutral with regard to jurisdictional claims in published maps and institutional affiliations. 